\title{
Influencers and Major Themes in a Gifted Education Community of Practice on Twitter
}

\author{
Erin M. Miller \\ Bridgewater College \\ Jennifer L. Jolly \\ University of Alabama \\ Jacqueline N. Latz \\ Bridgewater College \\ Kelsi Listman \\ Bridgewater College
}

\begin{abstract}
Author Note
Erin M. Miller (D) https://orcid.org/0000-0002-9448-037X

Jennifer L. Jolly (iD https://orcid.org/0000-0002-3848-3701

Jacqueline N. Latz (D) https://orcid.org/0000-0002-6272-2338

Kelsi Listman (iD https://orcid.org/0000-0002-9835-2586
\end{abstract}

We have no conflicts of interest to disclose.

Correspondence regarding this article should be addressed to Erin Morris Miller, Department of Psychology, 402 East College Street, Bridgewater, Virginia 22812 Email:

emmiller@bridgewater.edu 


\begin{abstract}
Twitter is a valuable resource for research because of its potential to provide insight into public opinions as well as identify whom are the most influential sources of information. However, false information spreads easily on Twitter and parents often trust online sources even when those ideas run counter to the information from professionals (Külhaş Çelik et al., 2019). Convergent mixed methods exploratory analysis was used to evaluate the discourse on Twitter regarding gifted education. The results of the quantitative analysis of the matrix of connections using NodeXL Pro indicate that gifted education Twitter is a cohesive network and that the top influencers are organizations and educational consultants. The qualitative analyses suggest that gifted education professionals and parents engage in Twitter in similar ways to what has been described in past research: to share interesting articles and videos, to discuss current issues, promote one's ideas, and seek opportunities.
\end{abstract}




\section{Influencers and Major Themes in a Gifted Education Community of Practice on Twitter}

Select individual's oversized role has been a constant in the dissemination of information. Katz (1957) first suggested that opinion leaders influence the flow of knowledge transmission. In the mid- $20^{\text {th }}$ century, individuals gained information from print, radio, or newsreel media. Currently, social media is a main source of information dissemination. Social media consists of online tools that facilitate virtual social interactions among different individuals (Dworkin et al., 2018), while social media networks are web-based applications in which individuals and groups connect to and interact with one another (Zyoud et al., 2018). Social media influencers are those individuals who have curated a greater effect on others' behavior through social media outlets and increased sharing of information (Alp \& Öğ̈̈dücü, 2018). Overall, Facebook, Twitter, LinkedIn, Snapchat, and Instagram are the most common social networks worldwide used by social influencers (Statista, 2020). This study focuses on the social media platform Twitter.

Twitter is a microblogging platform, established in 2006, that facilitates the sharing of real-time information, threads of dialogs, and development of social networks. Individuals post public messages of no more than 280 characters called "tweets" that may or may not include multimedia such as photos or hyperlinks. Individuals create public profiles with usernames beginning with the @ symbol. Profiles typically include short descriptions of the user. The profiles of individuals considered to be public figures can be verified, indicating a connection to a real person (only around 6\% of accounts are verified). Users can choose to "follow" other accounts, which partially determines which tweets one sees. Users can click "like" to express support or agreement with another account's tweet and can "retweet," meaning another user's tweet is shared on one's own account. When doing so one can directly retweet or they can "quote tweet" where the shared tweets is paired with a comment from the person retweeting it. Hashtags using the \# symbol are used to indicate that a tweet is part of a specific topic or group, for example \#gifted would indicate the post may be relevant to gifted education. Individuals can also include the username of other accounts in a tweet and this is described as "mentioning" another

user. Anyone with a Twitter account can search for tweets by username, hashtags, and keywords. Twitter has become a valuable resource for research because of its potential to provide insight into public opinions and views (Zhang \& Ahmed, 2019).

Twitter is ranked as among the most popular social media applications. In the United States around $25 \%$ of individuals use Twitter, including 38\% of those ages 18-29 and 26\% of those ages 30-49 years old (Perrin \& Anderson, 2019). According to the Pew Research Center, Twitter users are generally younger, more highly educated, have higher incomes and are slightly more likely to endorse liberal views (Wojcik \& Hughes, 2019) as compared to other social media users. Compared to other popular social media applications like Facebook where users more often share personal stories, Twitter users are more prone to like and retweet posts about intellectual topics (Marshall et al., 2020). Marshall et al. (2020) also reported levels of variability in how active different individuals are on Twitter. While the median user may only post two tweets a month, active Twitter users may post daily. In the United States, the top $10 \%$ of active users posted $80 \%$ of all tweets. Among these more prolific accounts the median number of followers is 387 and median number of accounts followed is 456. In addition, compared with other U.S. adults on Twitter, active users are much more likely to be women and report they regularly tweet about politics (Wojcik \& Hughes, 2019). 


\section{Twitter Use in the Educational Community}

Social media platforms can be used to create online social learning communities and can be a valuable resource for classroom teachers, researchers, scholars, clinicians, and parents. The concept of social learning discussed by Dewey in the 1950s and Bandura in the 1970s has continued into the digital world of professional learning networks (PLNs) through social media (Trust et al., 2018). Twitter has the potential to allow "just-in-time" affinity networks to develop so that educators may collaborate to address emergent educational needs (Greenhalgh \& Koeler, 2017). The self-directed nature of social media allows educators, parents, and other stakeholders to digitally engage with peers without time, space, or institutional barriers (Rinaldo et al., 2011; Stevenson et al., 2015).

Teachers generally found Twitter to be valuable tool in professional development, using the platform to learn about new technologies, tools, instructional strategies, and lesson plans (Prestridge, 2019; Trust et al., 2018; Tucker, 2019) as well as to engage in professional networking and personal promotion (Bommarito, 2020; Ross et al., 2015; Staudt Willet, 2019). Through an analysis of an online learning community on Twitter, Xinga and Goab (2018) concluded that educators were more likely to interact with tweets that focus on collaborating to generate professional knowledge. Staudt Willet's (2019) content analysis of tweets with the hashtag \#EdChat found that the majority of the tweets involved offering advice and sharing opportunities. The participatory nature of online professional learning networks may help teachers to overcome isolation (Carpenter \& Morrison, 2018; Davis, 2015; Ross et al., 2015; Trust et al., 2018; Tucker, 2019). A qualitative study with 15 classroom teachers, indicated that all participants used social media as their primary means of professional learning (Prestridge, 2019). Thirty-six classroom teachers and principals who participated in qualitative research reported that their connections with influential education leaders on social media were as meaningful and substantive as the information provided by live in-services and information from their district administration (Stevenson et al., 2015).

Higher education researchers, scholars, and clinicians can also leverage the opportunities that social media offers. Academics may use social media to share research findings, discuss major issues, share data, address misinformation, and engage in discussion about trending issues central to their respective fields (Sugimoto et al., 2017). Academics also can integrate current Twitter threads into their courses and mentor students in the use of Twitter for professional purposes (Ricoy \& Feliz, 2016; Smith-Risser, 2013). Educational institutions use Twitter to disseminate information such as news, events, and announcements (Kimmons et al., 2017). Professional conferences often have a Twitter hashtag, which fosters a participatory culture of tweeting about the sessions and lectures during and after a conference. Meeting participants also engage with Twitter to network, form professional connections, and gather information ( $\mathrm{Li} \&$ Greenhow, 2015; Luzón \& Albero-Posac, 2020). But not all posts connected to a professional meeting have equal effect or influence. Veletsianos and Kimmons (2016) studied the use of Twitter during American Educational Research Association's 2014 annual conference and found that the most influential accounts were those of professors from higher reputation universities. In addition to the uses of social media noted earlier, clinicians (e.g., educational and clinical psychologists) may also use social media as a method of self-promotion to find clients (Sultan et al., 2019). One major concern for these groups is the importance of maintaining client and student 
confidentiality (Baron \& Townsend, 2017), which may make some educators and clinicians hesitant to engage on Twitter.

Parents are often active users of social media (Niela-Vilén et al., 2014; Nieuwboer et al., 2013). Possible reasons parents engage with social media include connecting with others, improving parenting skills, seeking emotional support and self-validation, finding a space for selfexpression, information exchange, mental stimulation, and recording life events (Doty \& Dworkin, 2014; Dworkin et al., 2018; Jolly \& Matthews, 2017; Pettigrew et al., 2016). Parents with children with special needs may find mutual support in online groups (Alfredsson \& Broberg, 2016; Bellon-Harn, et al., 2020; Shepherd et al., 2020). Findings from several studies indicate a greater tendency for females to participate in online support groups, but the findings are mixed (Mo et al., 2009; Tifferet, 2020). A review of literature of online support groups noted that parents may consider the information from peers to be more useful than information provided by professionals such as researchers, scholars, teachers, or clinicians (Niela-Vilén et al. (2014).

Twitter live chats are one social media space in which parents, teachers, professors, and educational consultants come together. Twitter live chats are often structured to follow a format of questions and answers. Questions are used as prompts and are often indicated with Q1, Q2, and so on, while participants post their response beginning with A1 or A2 to correspond with the prompt being answered. A linked hashtag allows the chat to be followed in real time. Twitter chats are popular with teachers (Luo et al., 2017; Manca \& Whitworth, 2018), allowing for the examination of issues through multiple perspectives from around the world and participating teachers to increase their social connections over time (Rehm \& Notten, 2016).

However, scholars often worry about the spread of misinformation and disinformation through social media (Anspach \& Carlson, 2018; Jang et al., 2019; Wang et al., 2019; Wood, 2018). Swire-Thompson and Lazer (2020) define misinformation as assertions that are counter to the consensus of the scientific community of researchers/scholars in the field and with consensus may change as new evidence is published. Disinformation is the sharing of information that is intentionally false. It is often difficult to discriminate between misinformation and disinformation when the intention of the source and spreader are unknown. Regardless, misinformation is rampant (Scheufele \& Krause, 2019). For example, online sources that parents consult for information about gifted children may range from the Johns Hopkins Center for Gifted Youth website to less reliable sources such as personal blogs. As of 2016, the internet became Americans' primary source of information about science (National Science Board, 2018). Compounding the spread of misinformation and disinformation on the internet are confirmation bias and echo chambers.

Confirmation bias is one of the principal issues of concern. Confirmation bias is the tendency to seek information that supports previous beliefs, which leads to selectivity in seeking and applying evidence (Nickerson, 1998). Individuals clustering with others who will confirm their bias form an echo chamber where a single perspective is held by the group (Brugnoli et al., 2019; Del Vicario et al., 2016; Kim \& Dennis, 2019). Individuals within an echo chamber tend to ignore and dismiss information counter to their perspective (Zollo et al., 2017). The infinite amount of information online easily supports any hypothesis, allowing confirmation bias to 
thrive on social media platforms (Swire-Thompson \& Lazer, 2020). Vosoughi et al. (2018) found that novel false information spread further on Twitter than factual news, with many parents trusting online sources even those running counter to the information from professionals (Külhaş Çelik et al., 2019). As a result, the evaluation of the information shared in online learning communities is imperative.

\section{Analyzing Social Networks}

\section{Qualitative Content Analysis of Social Networks}

Given the relative newness of social media, approaches to qualitatively analyze these data are still emerging. There are even epistemological issues about the nature of social media data, and whether it reflects reality or creates reality (Jürgens, 2012; Tinati et al., 2014). The sheer volume of data available when studying social media platforms such as Twitter often precludes analysis by human coders (Murphy, 2017). However, when the focus of the analysis is sufficiently narrow, qualitative research is feasible. In a review of the types of published qualitative and mixed methods research articles, Snelson (2016) reported that the most common type of analytic approach was inductive content analysis. When it comes to research examining social media networks, several researchers have suggested using a mixed methods approach best captures both the content and the relational networks observed in social media (Domínguez \& Hollstein, 2014; Giglietto et al., 2012; Tinati et al., 2014).

\section{Sentiment Analysis}

One approach to developing an overall impression of the data set when it is too large for in-depth content analysis is to use automatic methods such as sentiment analysis. Sentiment analysis is the evaluation of written text or transcribed natural language to determine opinions, attitudes, emotions, and related concepts through automated processes (Liu, 2012). The goal is to measure subjective states rather than topics of discussion. Analysis of the large volume of textual datasets gathered in social media research often uses either machine learning, lexicon-based approaches, graph-based, or combination of multiple techniques to automatize the process (Batrinca \& Treleaven, 2015). Machine learning approaches involve training artificial intelligence programs to build an algorithm that can evaluate complex natural language data. Lexicon-based approaches use a dictionary of words that have been judged to indicate different emotions, beliefs, or other characteristics. An advantage of this technique is that it is relatively straightforward as the analysis simply searches through text for the words that have been included in the dictionary. For example, if a person posts the tweet, "Today was a great day working with my gifted students. I am so proud to be their teacher" the program would match the words great and proud to the dictionary, indicating a positive sentiment. As the analysis is independent of context, this approach can affect the accuracy of the analysis as a word may have differing sentiment depending on context. See Batrinca \& Treleaven (2015) for a primer on social media sentiment analyses for social scientists.

\section{Social Network Visualization}

A set of common vocabulary has developed to describe graphs of social networks (Borgatti et al., 2018; Findlay \& van Rensburg, 2018). Figure 1 shows a simple network of friends. The subjects 
of the study are called nodes. Nodes can be people, countries, organizations, etc. In the example, the nodes are people. The connections are called ties or edges. These connections can be anything that serves to connect two nodes. For the example, the connecting lines designate a friendship between the two individuals. For Twitter, these are relationships such as following, mentions, and retweets. Paths are sequences of nodes that do not pass through any single node more than once. In the example you can follow a path from Fran to Kate. Trails are sequences that revisit a node but do not revisit an edge. There is a trail from Fran to Jyn to Phil to Kate and back to Fran. Walks are sequences that revisit nodes and edges. Geodesic distance indicates the shortest path between to nodes. In the example the shorted path from Fran to Tess is through Kate or Will. Bridges are edges that connect areas of the graph. Cut points are edges that if removed would result in two or more separated graphs. For example, if one has separate work friends and childhood friends then your connections to each group would be cut points. In the example figure, the connection from Phil to Paz is a bridge that if cut would separate two groups.

\section{Figure 1}

Example of a Social Network of Friends

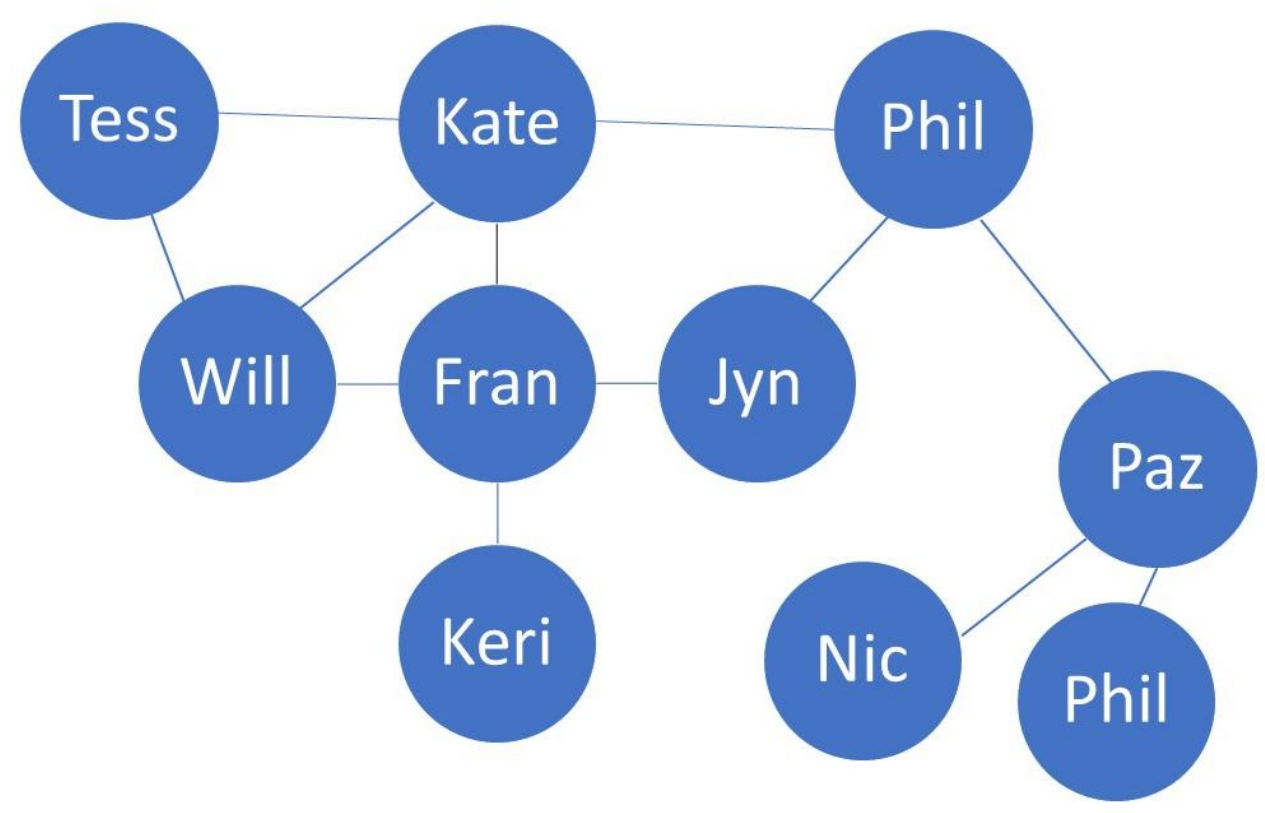

Current Study

This study is a convergent parallel mixed methods exploratory analysis of the discourse on Twitter regarding the education of children commonly labeled as gifted. Quantitative methods were used to determine which Twitter users could be considered influencers and the nature of the network of connections among these individuals. Qualitative content analysis was used to identify themes in the tweets and discussions about this population of students. A comparison of multiple types of machine learning sentiment assessments of the tone of the tweets will be presented in a separate article. 


\section{Methodology}

\section{Ethics Statement}

Approval for this study was obtained from the Bridgewater College institutional review board. As a requirement for approval, individual Twitter accounts identified as influential would need to be represented by a pseudonym, although organizations could be named. The quotes presented in the qualitative data did not require pseudonyms as the authors' tweets on the Twitter platform are public.

\section{Data Collection}

Tweets were obtained using the software QDA Miner (2020). This software allows one to download information from Twitter using several different possible search parameters. In this data collection hashtags were used as the search terms. The following hashtags were used to gather tweets: \#gifted, \#giftedEd, \#giftedminds, \#gtchat, and \#giftededucation. The initial query completed by QDA Miner collects tweets from seven days prior to the query and then tweets were gathered for seven additional days resulting in two weeks of Twitter data for each hashtag. The following nine data points were recorded for each tweet: (a) Tweet Date, (b) User ID Number, (c) User Name, (d) Screen Name, (e) Location, (d) Number of Followers, (f) Number of Total Tweets, (g) Retweets, and (h) Tweet Text. Twitter accounts may be created by individuals, organizations, schools, and businesses.

Snowball sampling was used to determine relevant hashtags. Data collection first occurred using the hashtag \#gifted. The subsequent hashtags were chosen based on examination of each wave of data for the most frequently included hashtags. The query for \#gifted yielded 1,527 individual tweets. This hashtag is also used to indicate receiving free merchandise and spiritual blessings. These unrelated tweets were discarded leaving 419 tweets that were related to gifted education. The other hashtags were used exclusively to tag information related to gifted children and their education. For these the yield was: \#giftedEd $(\mathrm{N}=47)$, \#giftedminds $(\mathrm{N}=116)$, \#gtchat $(\mathrm{N}=$ $314)$, and \#giftededucation $(\mathrm{N}=52)$. A second set of data was collected using \#gifted. This yielded 1,020 tweets, with 268 being related to gifted education. A total of 1,216 tweets were gathered. Duplicate entries (i.e., retweets) were removed leaving 710 unique tweets. To detect bias in sampling, the data was checked for adherence to the Newcomb-Benford law (Hill, 1998). The Newcomb-Benford law pertains to the distribution of first digits in naturally occurring data. The distribution is such that lower digits $(1,2,3)$ occur more frequently than higher digits and that this distribution follows a theoretical pattern. The leading digits of the number of followers of all unique accounts were examined. The distribution was consistent with the NewcombBenford law (See Figure 2) supporting the assertion that the sampling was not biased. 
GIFTED EDUCATION TWITTER 9

Figure 2

Distribution of Followers to Test for Adherence to Newcomb-Benford Law

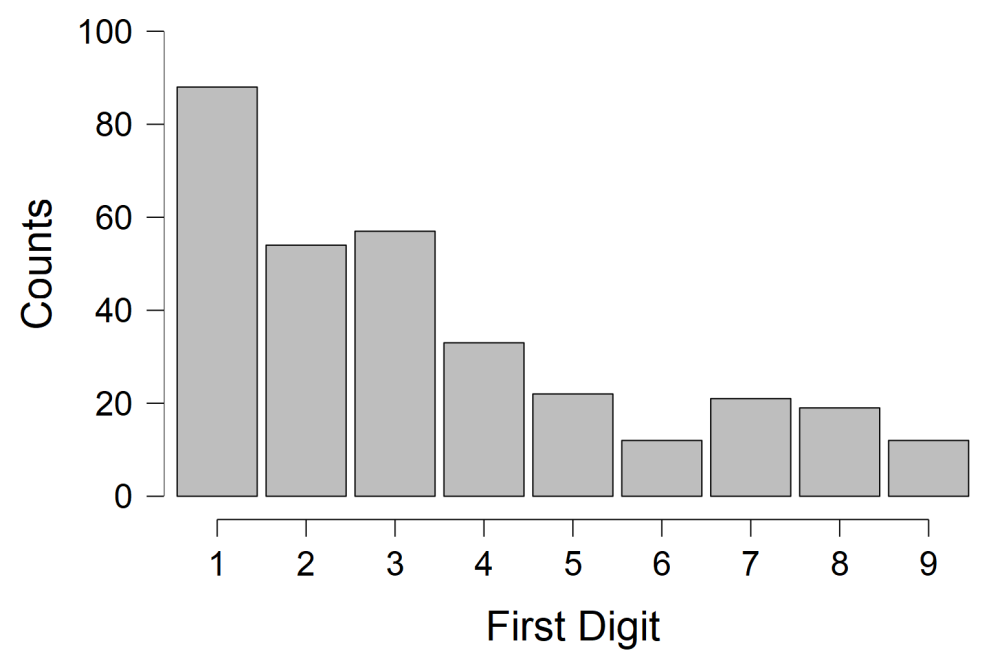

Determination of Influencers

There are several possible ways to determine who has the greatest influence on the Twitter platform. Total number of followers is one measure of influence. However, this can be misleading if many followers were gained because of reciprocated connections, which is when someone follows an account because the account first followed them (Alp \& Öğ̈̈ücü, 2018). Another metric is number of retweets. Retweeting is a measure of how far a tweet spreads to other Twitter users and indicates greater interaction and consumption of the tweet's content. The software NodeXL Pro was used to determine additional metrics of influence. NodeXL Pro is an open-source template add-on to Microsoft Excel that facilitates analyses of large networks (Smith et al., 2010). Common metrics include in-degree and betweenness centrality (Pei et al., 2014; Riquelme et al., 2018; Tsugawa \& Kimura, 2018). In-degree centrality is a count of how many unique connections point to a vertex. In the case of Twitter, this is the number of unique followers. Betweenness centrality is the extent that the vertex lies at the shortest distance between multiple other vertices. This measure helps identify individuals who are a bridge between others in the network.

\section{Twitter Posts-Qualitative Content Analysis}

The content of the tweets was analyzed using inductive data analysis (Miles, et al., 2014). Specifically, open coding was completed followed by axial coding to identify major themes (Strauss \& Corbin, 1998). During the open coding, two undergraduate research assistants (Latz and Listman) independently coded the 710 tweets. Latz identified 79 topics. Listman identified 90 possible topics. Miller then used axial coding to identify connections among these topics. The first step was to examine each open coding dataset and look for similar themes between the two research assistants, which then could be given a common label. For example, one research assistant labeled a theme "being gifted isn't easy" while the second assistant labeled the same set of tweets as "Challenges to being Gifted." A consistent label was agreed upon. Then Miller combined overlapping or similar themes across these two sets of analyses. For example, 
combining all tweets related to sharing different curricular strategies into a single "Curriculum and Programming" theme rather than by topic (reading, math, social studies, etc.)

Miller reviewed, combined, and consolidated the tweet topics developed by the research assistants into 28 major themes plus one category labeled as "Outlier" which included tweets that did not fit into other themes and were not connected to a common topic in gifted education (See Table 1). Examples of tweets in the "Outlier" category include a parent talking about her gifted children doing a good job on their chores and a tweet about a gifted education researcher having trouble writing because of concerns about his family in Iran. The 28 themes were sent back to the research assistants who each agreed that these themes seemed to reflect their impression of the major ideas discussed in the tweets.

\section{Table 1}

Themes with Counts Arising from the Qualitative Content Analysis

\begin{tabular}{lrr}
\hline \multicolumn{1}{c}{ Theme } & Count & Percent \\
\hline Twitter Chat Announcement & 80 & 11.268 \\
Parent School Relationship & 80 & 11.268 \\
Curriculum and Programming & 74 & 10.423 \\
Parenting Gifted & 56 & 7.887 \\
Advocacy & 52 & 7.324 \\
Challenges to Being Gifted & 50 & 7.042 \\
Gifted Teacher Ed & 49 & 6.901 \\
Conference Announcements & 41 & 5.775 \\
Gifted in School & 32 & 4.507 \\
Underrepresented Groups & 32 & 4.507 \\
Assessment and Identification & 21 & 2.958 \\
Beliefs About Giftedness & 20 & 2.817 \\
Gifted is more than Academics & 18 & 2.535 \\
Twice Exceptional Children & 16 & 2.254 \\
Gifted Book & 15 & 2.113 \\
Overexcitability & 12 & 1.690 \\
Importance of Creativity & 11 & 1.549 \\
Gifted Adults & 9 & 1.268 \\
Researchers Sharing Research & 7 & 0.986 \\
Gifted Summer Camps & 6 & 0.845 \\
Multiple Intelligences & 4 & 0.563 \\
Art/Literature Appreciation & 3 & 0.423 \\
Gifted Blog Promotion & 3 & 0.423 \\
Online Journal Promotion & 2 & 0.282 \\
Gifted Research Collaborations & 1 & 0.141 \\
Grant Opportunity Announcement & 1 & 0.141 \\
Multipotentialities & 1 & 0.141 \\
Gifted Organization Promotion & 13 & 0.141 \\
Outliers & 1.831 \\
\hline & & \\
& &
\end{tabular}


Jolly separately conducted a qualitative analysis using open coding to systematically review the 710 tweets according to the guidelines provided by Miles et al. (2014). She began by reading all 710 tweets, continually noting any emergent categories. A second reading of the tweets took place and categories were again noted. By eliminating duplicates and combining similar categories, 56 categories were noted. During axial coding process, these initial categories were further refined using the constant comparative method, providing 8 codes. Finally, during the selective coding phase, 3 overarching themes emerged-(a) particulars and essentials, (b) knowledge dissemination, and (c) engagement.

The 28 sub-themes from the earlier qualitative content analysis were then sorted by Miller into the three overarching themes identified by Jolly (See Table 2). Twenty percent of the tweets fit into the overarching theme of Particulars and Essentials. These tweets consisted of announcements and promotional tweets. For the Knowledge Dissemination theme, Jolly organized the tweets according to the source of the information while research assistants Latz and Listman organized these same tweets according to the topic of the information. A little over a third (34.2\%) of the tweets fell into this category. The third major theme, Engagement, included tweets involving the discussion of major topics such as parent-school relationship, underrepresented groups, neurodiversity, and lifespan development. These topics encompassed $43.8 \%$ of the tweets.

\section{Qualitative Trustworthiness}

Credibility and Transferability. The qualitative analogs to reliability and validity of research methods in this study were established through credibility, transferability, and dependability as defined by Lincoln and Guba (1985). Credibility was accomplished through triangulation and member-checking. The two research assistants evaluated the tweets separately and then worked together to resolve differences. Dr. Jolly independently assessed the tweets. The separate analyses were in concordance. These analyses were then sent to Ophélie Desmet who is an assistant professor in the College of Education and Human Services at Valdosta State University and the webmaster/social media coordinator for the AERA Research on Giftedness, Creativity, and Talent Development Special Interest Group. She affirmed that the themes reflected her experience on Twitter. Transferability is determined by thick description. We have endeavored to provide sufficient description of the qualitative methods and results to allow other researchers to apply the results to other educational fields. See Figure 3 for a visual representation of the methods. 


\section{Table 2}

Triangulation of Themes from Content Analysis and Open Coding

\begin{tabular}{|c|c|}
\hline Triangulation Themes & Content Analysis Themes \\
\hline \multicolumn{2}{|l|}{ Particulars and Essentials } \\
\hline $\begin{array}{l}\text { Announcements } \\
\text { Opportunities }\end{array}$ & $\begin{array}{l}\text { Twitter Chat Announcement } \\
\text { Conference Announcements } \\
\text { Researchers Sharing Research } \\
\text { Gifted Summer Camps } \\
\text { Online Blog Promotion } \\
\text { Online Journal Promotion } \\
\text { Gifted Organization Promotion } \\
\text { Grant Opportunity Announcement } \\
\text { Gifted Research Collaborations }\end{array}$ \\
\hline \multicolumn{2}{|l|}{ Knowledge Dissemination } \\
\hline $\begin{array}{l}\text { Organized by Source: } \\
\text { Consultants } \\
\text { Organizations } \\
\text { Books } \\
\text { Web-Based }\end{array}$ & $\begin{array}{l}\text { Organized by Topic: } \\
\text { Curriculum and Programming } \\
\text { Advocacy } \\
\text { Gifted Teacher Ed } \\
\text { Gifted in School } \\
\text { Assessment and Identification } \\
\text { Gifted Book }\end{array}$ \\
\hline \multicolumn{2}{|l|}{ Engagement } \\
\hline $\begin{array}{l}\text { Stakeholders } \\
\text { Discussions } \\
\text { Airing of Grievances }\end{array}$ & $\begin{array}{l}\text { Parent-School Relationship } \\
\text { Underrepresented Groups } \\
\text { Twice-Exceptional Students } \\
\text { Gifted Adults } \\
\text { Parenting Gifted Children } \\
\text { Beliefs About Giftedness } \\
\text { Overexcitabilities } \\
\text { Importance of Creativity } \\
\text { Multiple Intelligences } \\
\text { Art/Literature Appreciation } \\
\text { Multipotentialities } \\
\text { Challenges to Being Gifted } \\
\text { Gifted is More than Academics }\end{array}$ \\
\hline
\end{tabular}




\section{Figure 3}

Graphic Representation of Qualitative Analysis

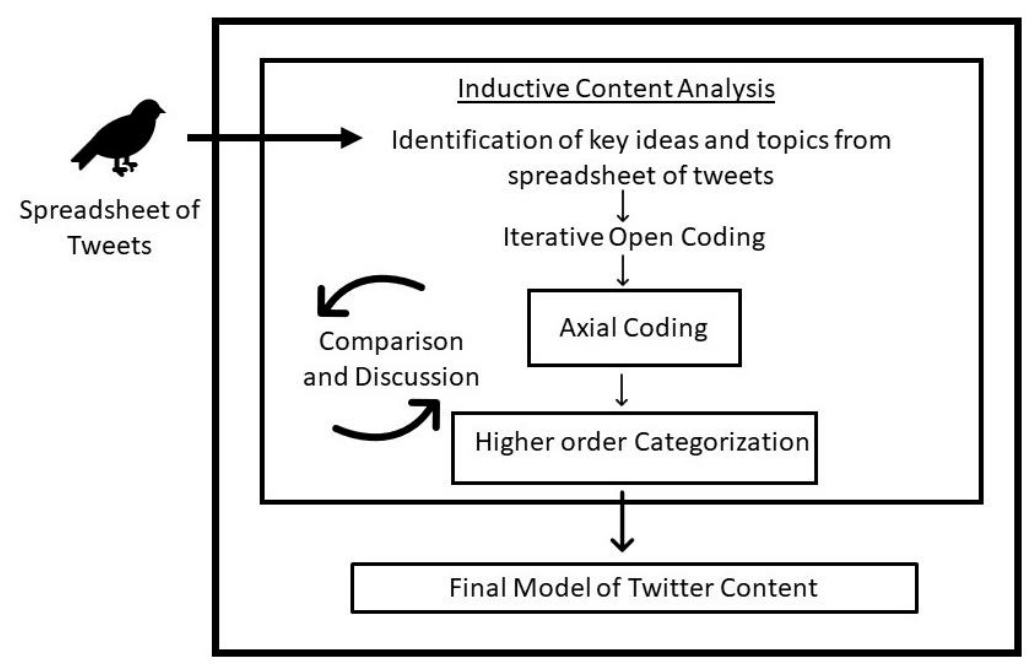

Dependability: Researcher as Instrument. One of the determinants of quality in qualitative research is the dependability of the researchers (Lincoln \& Guba, 1985). Part of determining dependability is the credentials of the researchers as well as recognition of possible bias in the individuals who are serving as the instruments of the analysis.

Erin Morris Miller holds a PhD in Educational Psychology with an emphasis on gifted education and research methods. She has been involved in the field of gifted education for 20 years and has held leadership positions in the NAGC and the Research on Giftedness, Creativity, and Talent (RGCT) Special Interest Group of the American Educational Research Association. Her motivation to complete the analysis was curiosity and a desire to learn social media analyses techniques. Dr. Miller completed the literature review and quantitative analyses. The other researchers did not read the literature review before completing their qualitative analysis.

Jennifer L. Jolly holds a PhD in Educational Psychology with an emphasis in gifted education. Her experience in gifted education began 25 years ago as a gifted pull-out teacher before moving to higher education as professor of gifted education. She has been actively involved in NAGC, The Association for the Gifted (CEC-TAG), and AERA-RGCT SIG. Jolly's motivation stemmed from her experiences across these three organizations and her work with families of gifted children.

The undergraduate research assistants' motivation to complete the analysis was to improve their research skills and to pursue a personal interest in Twitter research. This experience will also enhance their applications when seeking employment and/or graduate school in psychology. The students had participated in programs for gifted students during their K-12 education. One was in the process of completing an undergraduate honors program. Each of the students had completed research methods and measurement/statistics courses. The students were given additional instruction in qualitative content analysis principles before beginning their analysis. 
GIFTED EDUCATION TWITTER 14

\section{Results}

\section{Quantitative Determination of Influencers}

These accounts had the largest number of followers: Mindshift ( 355,000 followers), American Mensa ( 21,900 followers), the National Association for Gifted Children (NAGC, 17,500 followers), the Social Emotional Needs of the Gifted (SENG, 13,000 followers), and British Mensa ( 12,700 followers). Mindshift was identified as an extreme outlier as compared to the other accounts. Mindshift is a podcast about learning writ large, and it is produced by National Public Radio. As it is outsized in its number of followers and scope, it was removed from further consideration in the quantitative analysis (but retained in the qualitative analysis) to focus on accounts that post specifically about issues related to gifted education.

Each set of data (a set for each hashtag) was sorted according to number of retweets. Users who produced content that was retweeted at least once were identified as potential influential users. Eighty-one potential influencers were identified based on retweets. The accounts NAGC (188 retweets), Evelyn Simon (pseudonym, 142 retweets) and Social and Emotional Needs of the Gifted (SENG, 63 retweets) had the largest number of retweets.

A directed matrix of connections was created using Microsoft Excel connecting the different potential influencers based on whom follows whom on Twitter. This matrix was then analyzed using NodeXL to determine metrics indicating which accounts are central to the social network. The following accounts had the greatest in-degree centrality: NAGC, SENG, Summer Institute for the Gifted, Myra Patrick (pseudonym), and the Belin-Blank Center. The accounts of the GT Chat (through the Texas Association for the Gifted and Talented), NAGC, SENG, Dr. Lucy Sanders (pseudonym), and the Summer Institute for the Gifted had the greatest betweenness centrality.

Each metric (followers, re-tweets, in-degree centrality, and betweeness centrality) was standardized into z-scores and summed to create a composite measure of influence for each Twitter account. The following 20 accounts were identified as the top influencers: NAGC, SENG, American Mensa, the Belin-Blank Center, the G-Word film, GT Chat, Dr. Jeffrey Mann (pseudonym), Evelyn Simon, Duke Talent Identification Program, Summer Institute for the Gifted, Dr. Lucy Sanders, Faye Stephens (pseudonym), Elizabeth Martin (pseudonym), Dr. Nina Townsend (pseudonym), Western Kentucky Center for Gifted Studies, Prufrock Press, Simon Holland (pseudonym), Myra Patrick, Arizona Association for Gifted and Talented, and Dr. Terrence Ingram (pseudonym). See Table 3 for a description of top influencer accounts. 
Table 3

Top Twenty Influencers from Quantitative Analysis Ranked 1-20

\begin{tabular}{|c|c|c|}
\hline Rank & Account & Description \\
\hline 1 & $\begin{array}{l}\text { The National Association } \\
\text { for Gifted Children (NAGC) }\end{array}$ & $\begin{array}{l}\text { US non-profit organization to support the needs of } \\
\text { gifted, talented, and creative children }\end{array}$ \\
\hline 2 & $\begin{array}{l}\text { American and British } \\
\text { Mensa }\end{array}$ & $\begin{array}{l}\text { National organizations for individuals with high IQ } \\
\text { scores }\end{array}$ \\
\hline 3 & $\begin{array}{l}\text { The Social Emotional Needs } \\
\text { of the Gifted (SENG) }\end{array}$ & $\begin{array}{l}\text { US non-profit organization focusing on the } \\
\text { development and self-actualization of gifted, } \\
\text { talented, and creative individuals }\end{array}$ \\
\hline 4 & Evelyn Simon* & $\begin{array}{c}\text { Author and parent who homeschooled her gifted } \\
\text { children }\end{array}$ \\
\hline 5 & $\begin{array}{l}\text { The Summer Institute for } \\
\text { the Gifted }\end{array}$ & $\begin{array}{l}\text { Organization providing summer programs for } \\
\text { children ages 5-17 at multiple colleges, universities, } \\
\text { and private schools in the United States }\end{array}$ \\
\hline 6 & Myra Patrick* & $\begin{array}{l}\text { Educational consultant who works at the US state } \\
\text { level with parents to advocate for gifted children. }\end{array}$ \\
\hline 7 & The Belin-Blank Center & $\begin{array}{c}\text { A research, advocacy, and psychological clinic } \\
\text { focusing on the needs of gifted students at the } \\
\text { University of Iowa. }\end{array}$ \\
\hline 8 & GT Chat & $\begin{array}{l}\text { Moderator of a weekly Twitter chat through the } \\
\text { Texas Association for the Gifted \& Talented }\end{array}$ \\
\hline 9 & Lucy Sanders* & Clinical psychologist and author \\
\hline 10 & The G-Word & A crowd-sourced documentary about giftedness \\
\hline 11 & Duke Talent Identification & $\begin{array}{l}\text { Center that provides enrichment and acceleration } \\
\text { programs for gifted children and conducts research }\end{array}$ \\
\hline 12 & Prufrock Press & Publisher that focuses on gifted education \\
\hline 13 & Jeffrey Mann* & $\begin{array}{l}\text { University level gifted education program } \\
\text { coordinator and educational consultant }\end{array}$ \\
\hline 14 & Faye Stephens* & Educational consultant \\
\hline 15 & Elizabeth Martin* & Licensed counselor and author \\
\hline 16 & Nina Townsend* & $\begin{array}{c}\text { Research psychologist, author and educational } \\
\text { consultant }\end{array}$ \\
\hline 17 & $\begin{array}{l}\text { Western Kentucky Center } \\
\text { for Gifted Studies }\end{array}$ & $\begin{array}{l}\text { University program providing courses in gifted } \\
\text { education for preservice and practicing teachers as } \\
\text { well as programming for children }\end{array}$ \\
\hline 18 & $\begin{array}{l}\text { Arizona Association for } \\
\text { Gifted and Talented }\end{array}$ & State organization supporting gifted children \\
\hline 19 & Simon Holland* & State level gifted education administrator \\
\hline 20 & Terrence Ingram* & Associate professor of education \\
\hline
\end{tabular}


NodeXL was used to create a visual map of the connections among the 83 influencers. The graph was first laid out using the Fruchterman-Reingold (1991) algorithm which creates a layout with relatively equal length edges and minimizes edge crossings. Then accounts with largest numbers of retweets were pulled to the top of the graph. Finally, accounts that followed NAGC, but not SENG and vice versa were separated and moved to the bottom. This directed matrix graph has 83 vertices (one for each account) and 2014 connections or edges. Forty-six percent of the connections were reciprocated. The matrix was a single connected social network, meaning that any vertex can be reached by following a path beginning at any other vertex. The maximum geodesic distance is 3 edges, with an average of 1.56 edges. This indicates that the social network is highly interconnected. Density is a measure of the ratio of the number of connections over the total number of possible connections. This metric ranges from 0 in which there are no connections and 1 in which all nodes are connected to all other nodes. The density equaled .31 for the social network of gifted education Twitter influencers.

Each account is represented by a node in Figure 4. If Account A follows Account B then there is an arrow from node A to node B. If the two accounts follow each other, then the arrow is double headed. The shape of the node indicates the type of account. Circles indicate individual parents, teachers, or administrators. Squares are organizations, diamonds are consultants or bloggers, and triangles are professors/schools. Determination of which category an account belonged to was based on the description of the account provided in the Twitter profile. Forty-seven percent are parents, teachers or administrators. Twenty-two percent are consultants and $21 \%$ are organizations. The remaining $10 \%$ are professors/schools. The size of the node indicates total number of retweets. Accounts that with greater numbers of tweets being retweeted are larger in size.

The open-source statistical analysis program JASP was used to compare the top 20 influencers to the remaining 61 accounts. The two groups were compared according to total tweets and the age of the account. Mann-Whitney $U$ test was used due to violations of normality. The top influencers had significantly older accounts $(M=8.1$ years, $S D=3.5)$ and published more total tweets $(M=5258.4, S D=3347.4)$ than the less influential profiles, $(M=5.4$ years, $S D=3.5)$ and $(M=2293.4, S D=2634.7)$. For age, $U=212, p=.006$, and for total number of tweets, $U=620$, $p<.001$. 


\section{Figure 4}

Gifted Education Twitter Social Node Analysis

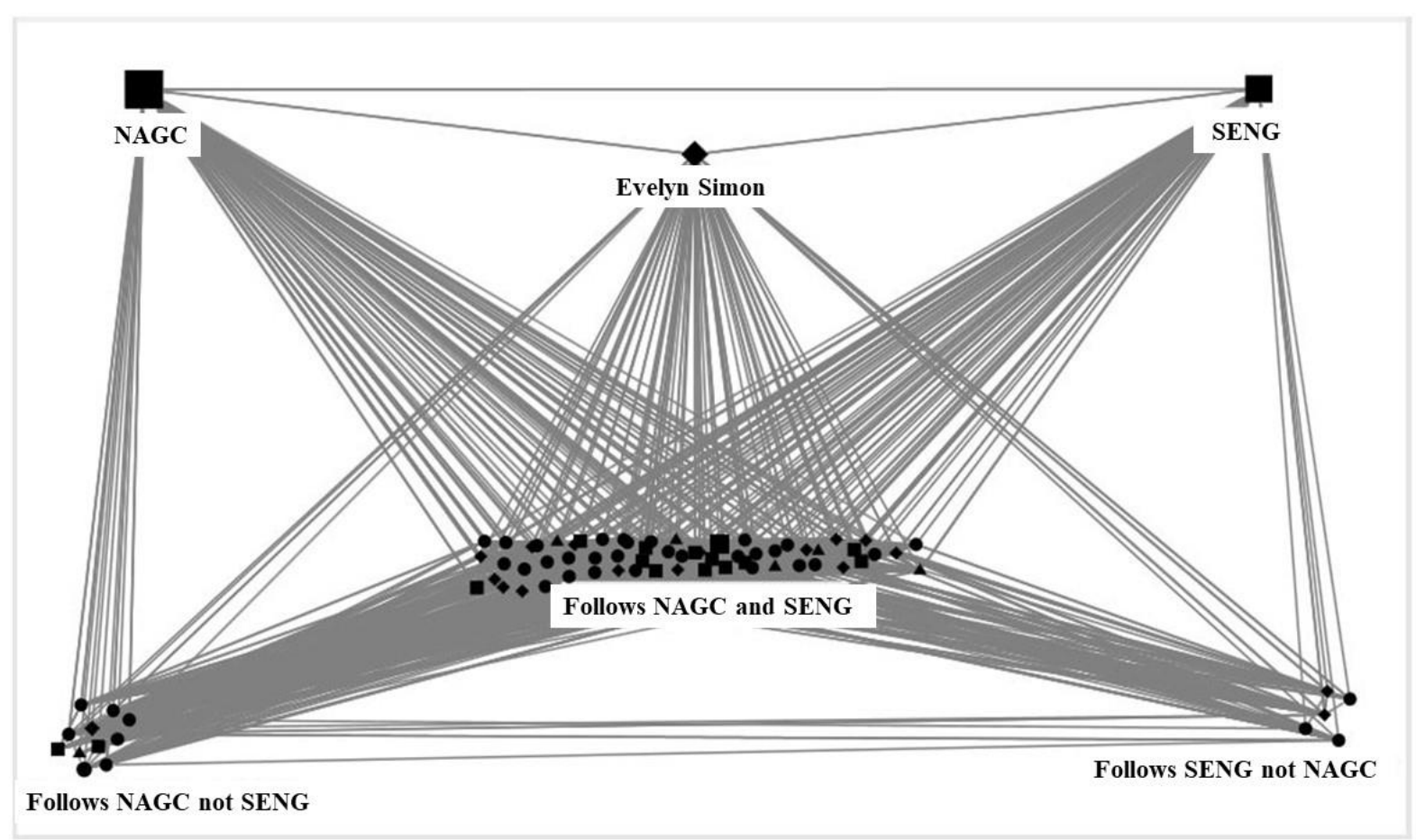

\section{Qualitative Content Analysis}

The overarching category of "Particulars and Essentials" contain tweets regarding announcements and promotion of different programs and opportunities. The majority of these involve announcements about the weekly Twitter chat organized by the Texas Association for the Gifted and Talented (TAGT). For example:

$\mathrm{Hi}$, all! My tweets for the next hour will be devoted to Global \#gtchat (\#gifted \#talented) Powered by \#TAGT. Please join the conversation! (gtchat, 2019)

Other tweets in this category include tweets promoting national and local conferences such as the annual conference of the American Educational Research Association (AERA) posted by the AERA Special Interest Group on Research on Giftedness, Creativity and Talent Development,

\#AERA20 will be here before we know it! Mark your calendar for these sessions and events from the @AERA_GiftedSIG. \#gifted \#creativity \#talent (AERA ROGCT SIG, 2020)

Twenty percent of the tweets fall into this category. Other common tweets included an announcement regarding the California Association for the Gifted, enrichment opportunities such as the Summer Institute for the Gifted, and promotion of websites such as the Gifted Homeschoolers Forum. 
The overarching theme of "Knowledge Dissemination" included educational consultants, major organizations, researchers, and writers sharing information meant to improve advocacy, teacher education, assessment, and curriculum/programming for gifted children at home and in school. Organizations often share information related to their area of expertise such as this tweet shared by Johns Hopkins Center for Talented Youth (CTY) which includes a link to an article about what parents should know about acceleration on the Bright Minds blog.

Is having your child skip a grade a good idea, or is there a better way to accelerate very bright kids in school? ?? https://t.co/PQXzUS28vg \#gifted \#parenting \#K12 \#acceleration (Johns Hopkins CTY, 2020)

Educational researchers who work in gifted education often use Twitter to share journal articles that they think would be of interest or useful to their followers. Scott Peters from the University of Wisconsin-Whitewater tweeted a message from Sarah Cohodes regarding her publication on the effect of accelerated coursework on increasing the number of students from minoritized groups attending college. Peters wrote in his tweet:

Everyone in gifted ed should read this article and this thread. So much really strong empirical work on \#gifted is being done by economists. @ NAGCGIFTED @ JonathanPlucker (Peters, 2020)

Another type of information dissemination is sharing local and national news related to gifted education. The status and proposed changes to gifted programming in the US city of New York was one example of this type of tweet. Jeffrey Shoemaker, who is an Education Program Specialist for Gifted Services at the Ohio Department of Education, tweeted:

Taking something away from some is not equity for all. Expand programs, use different methods of identification. Elimination is just giving up. \#gtchat \#nycgifted https://t.co/GktvX57GR3 (Shoemaker, 2020)

These two overarching themes reveal the practical uses of Twitter in conveying information to those stakeholders interested in the gifted and talented education. These tweets were also captured during an ongoing state conference and a several months before the start of a different one, so organizers used their Twitter accounts to take an opportunity to reach attendees. Additional tweets alerted users to essential and new information about a topic.

Of the overarching themes, the greatest percentage of tweets fell into the category of "Engagement." These tweets involve perceptions of major stakeholders and discussions of challenges and major issues in the field of gifted education. Tweets regarding parenting gifted children were a major theme of this category. Many of the tweets were reflections on challenges. Jen Torbeck Merrill tweeted,

School MUST start by truly listening to parents \& their concerns. I lost track of the number of times I was patronized and ignored, simply because they were the "experts" \& I was simply the "parent." \#gtchat (Merrill, 2020) 
This category also reflects discussions of disagreements among gifted education professionals. Teacher and educational consultant Clint Rodriguez tweeted,

I think it's critical that schools communicate what the research actually says about giftedness. There are so many myths being propagated by so many different organizations about the supposed social emotional fragility of gifted students. \#gtchat (Rodriguez, 2020)

While the organization Supporting Emotional Needs of the Gifted (SENG) tweeted,

Having high sensitivity makes \#gifted individuals especially susceptible to mental health issues, such as depression and anxiety. Sound familiar? (SENG, 2019).

The mental health of gifted students and the validity of concepts such as overexcitabilities is an ongoing area of discussion in the field of gifted education.

The category of Engagement includes what is arguably one of the top concerns in gifted education, the identification and service of minoritized students. This was a common topic of tweets posted by the National Association for Gifted Children (NAGC) such as the following tweet which contained a link to a November 11, 2019 Education Week article, "What We're Getting Wrong About Gifted Education,”

Treating giftedness as an in-born trait has resulted in severe underrepresentation says @ JosephRenzulli. Learn what he thinks \#educators must recognize when it comes to \#gifted programs in @educationweek. \#edequity https://t.co/4ruB9E0EPC (NAGC, 2019).

NAGC Executive Director John Segota tweeted about the article, "Iniquities in Advanced Coursework" by Kayla Patrick, Allison Rose Socol and Ivy Morgan on The Education Trust webpage,

"When advanced opportunities are extended to students of color and when teachers receive training and resources, these students thrive alongside their peers" | Inequities in Advanced Coursework https://t.co/q1MM4Gmqj1 via @EdTrust \#GiftedMinds \#Giftedness (Segota, 2020)

MindShift, a National Public Radio supported podcast and newsletter, tweeted the following in reference to changes to gifted programing in Memphis, Tennessee,

District leaders want to make sure qualified students who have been overlooked are truly integrated into the district's gifted program. Otherwise, inequities will persist @ ChalkbeatTN \#edchat \#gifted (MindShift, 2020) 
Diversity in the form of neurodiversity and twice-exceptionality was another common theme under the umbrella of "Engagement." The non-profit volunteer organization, Gifted Homeschoolers Forum shared a link to a blog by Aurora Remember Holtzman in the tweet,

What Exactly is Twice Exceptionality? It's not so much the services that made the difference in their success, but recognizing how their gifts and challenges interact and inspiring them to use their strengths. \#gtchat \#gifted \#2e\#TwiceExceptional https://t.co/W219FyVkr9 (GHF Learners, 2020)

Several of the tweets in this category could also have been characterized as announcements or knowledge dissemination. For example, in the tweet below Matt Zalaznick, a writer for the online magazine District Administration, linked to an article about twice-exceptionality,

Twice-exceptional students: What districts need to know and do to support this population https://t.co/oGzWK116SN \#k12 \#gifted \#specialed (Zalaznick, 2020)

This group of tweets differed from the first two overarching themes based on the composition of the tweet. The tweets posed questions rather than being declarative statements, asking followers to consider the information provided in an included link or posed in the tweet. These tweets also include polemic statements that intentionally draw the reader in (regardless of purposefulness). Tweets in this category came from many different stakeholders, but the majority were from parents, teachers, and professional gifted education consultants. There were less tweets in this category from organizations, such as NAGC, and researchers/professors.

\section{Limitations}

One limitation of the study is that data collection took place from November 2019 through February 2020. One cannot be sure that this period of time is representative of the community of individuals tweeting about giftedness, particularly given information about conferences being included within several of the identified hashtags. Transferability is determined by thick description. We have endeavored to provide sufficient description of the qualitative methods and results to allow other researchers to replicate the study with other educational fields, however the results may not apply to discussions of other domains of study on Twitter. Although efforts were made to avoid bias in the qualitative analyses, it is impossible to be $100 \%$ sure that an individual's prior beliefs did not influence how they perceived the tweets. This is an exploratory study and thus there were no established hypotheses going into the analysis. Additional confirmatory work should be completed. Although Twitter is a world-wide platform, this study focused on hashtags that were in English. The majority of accounts captured in this study were from North America. Thus, the results are most representative of the field of gifted education in the United States and to some extent, Canada. This study should be replicated with different hashtags to capture other online communities and contexts. 
GIFTED EDUCATION TWITTER 21

\section{Discussion and Implications}

In this exploratory study of individuals who were connected through their interest in gifted education, we sought to understand the nature of the discourse and the characteristics of influential Twitter accounts. The analysis of connections among the 83 accounts, using the NodeXL program, indicates that the group of individuals in this study constitutes a single network where all the members can be connected through direct or indirect connections. The maximum geodesic distance was three edges. This is a similar concept to "degrees of separation" or the popular parlor game Six Degrees of Kevin Bacon where a chain of "friend of a friend" can lead to any other person in the world. The network in this study revealed that the individual accounts are connected by no more than two other accounts. The density of a network is a measure of how many total connections exist as compared to how many connections are possible. For this affinity network, density was $31 \%$. This suggests that the Twitter network described in this study is a single relatively interconnected network that could be considered a personal learning network. Personal learning networks (PLN) are groups of individuals who are connected to each other in such a way that there is the potential for sharing insights/ideas and engaging in discourse over time, leading to personal and professional development (Hass, et al., 2020; Goodyear, et al., 2019). Britt \& Paulus (2016) note that social media networks have characteristics that are similar to in-person communities of practice such as sustained relationships, rapid flow of information, mutually defining identities, shared stories, and a shared discourse.

Forty-seven percent of the accounts in the network belonged to individual parents, teachers, or administrators. We grouped these three types together because they represented accounts that appeared to be individuals seeking and sharing knowledge. The network consisted of $22 \%$ educational consultants who in addition to possibly being parents or former teachers, also may participate in Twitter networks as a way of connecting with potential clients and reserving speaking engagements. Twenty-one percent of the accounts were organizations and 5\% were schools. Five percent of accounts in the network belonged to educational researchers and/or professors. This suggests that within this network the dominant source of information comes from individuals outside of academia. This network also reflects a small number of influential accounts when compared to other fields. Gifted education is a small field so the limited number of influencers may not be surprising.

In the graph presented in Figure 4, the accounts with the most retweets were pulled to the top as retweets are one of the most consistent indicators of influence (Essaidi, et al., 2020). The three accounts are NAGC, SENG, and the educational consultant and professional speaker, Evelyn Simon (pseudonym), each of whom follow the other. The majority of the accounts in the network follow NAGC, SENG, and Evelyn Simon. Eleven accounts followed NAGC but not SENG and five accounts followed SENG but not NAGC. Interestingly, the accounts that follow SENG but not NAGC did follow Evelyn Simon and each of those accounts mention "intensity" in their Twitter profiles. The eleven accounts that followed NAGC but not SENG were a mix of parents, teachers, and administrators. The following sections of the discussion go into greater detail regarding the profiles of the influential accounts. 
GIFTED EDUCATION TWITTER 22

\section{Characteristics of Influencers}

Accounts with the largest number of followers tended to be national organizations such as American Mensa, NAGC, SENG, and British Mensa. These accounts are quite different in their stated aims. Mensa is an organization for individuals with exceptional IQ scores and focuses on providing enrichment for their members. NAGC has the broad goal to support the development of gifted and talented children through multiple avenues including professional development, advocacy, community building, and research. The goals of SENG are narrower and focus on the social and emotional needs of children and adults with exceptional cognitive abilities. Although these organizations have thousands of followers $(12-21,000)$ and this would be considered as having a large influence in the realm of gifted education, it is substantially less than other educational Twitter accounts. Disability Scoop has $\sim 40,000$ followers. The magazine Teach Primary has $\sim 67,000$ followers. Edutopia has 1.1 million followers. Top celebrity accounts such as Justin Beiber have upwards of 100 million followers. Thus, the gifted education Twitter community is small as compared other educational accounts and Twitter in general.

Retweet counts are an important metric of influence as they indicate an increased reach of a single tweet. NAGC and SENG were top accounts according to this metric as well. However, the inclusion of an individual (Evelyn Simon) among the top retweeted accounts is noteworthy because of the power that can be gained by a single person in the realm of social media. Evelyn Simon evolved from public school teacher to a homeschooling parent of twice-exceptional children, to blogger, to author, to professional gifted education consultant and speaker. In her blog she indicates that her writing resonated with parents and that her progression to a professional author, speaker, and consultant grew from there. She represents what one might label the "Homegrown GT Expert."

The influence metrics of in-degree and betweeness centrality are based on the interactions among the 83 individuals identified as potential influencers based on retweets. In-degree centrality is a measure of how many unique followers that an account has as compared to others in the matrix of 83 accounts. The term "unique followers" means accounts that only follow that specific account and not the others. In-degree centrality is analogous to the person in high school that everyone wanted to befriend and know about. NAGC, SENG, the Summer Institute for the Gifted, the Belin-Blank Center, and Myra Patrick (pseudonym) had the highest number of unique followers. The Summer Institute for the Gifted is a summer enrichment program with sites at colleges and universities across the United States. To be eligible students must provide documentation of performance at or above the $95^{\text {th }}$ percentile on tests of academic, cognitive/creative ability or documentation of participation in their local schools' gifted program. Costs to parents range from $\$ 1,495$ to $\$ 6,899$ depending on the type of program. The BelinBlank Center is housed at the University of Iowa and runs a multitude of programs including professional development and certification for teachers, clinical psychological services, summer enrichment programs, and it serves as a research center. The Belin-Blank Center is well known for its work in supporting academic acceleration. Myra Patrick is a professional educational consultant who has held leadership positions in state level advocacy groups for gifted children. She is also a blogger, Facebook group manager, and active member of Twitter chats. She is another example of the influence that an individual can gain within social media networks. 
Betweenness centrality is a measure of how well connected an account is with multiple other accounts. In the high school analogy, this person is the individual who seems to be friends with everyone. Interestingly there was some overlap between in-degree and betweeness centrality as NAGC, SENG, and the Summer Institute for the Gifted also had high betweenness centrality scores. This means that there are many reciprocated connections where each account is following the other. In addition, the GT Chat account and an individual, Dr. Lucy Sanders (pseudonym), had high betweeness centrality. The GT Chat is a weekly chat supported by the Texas Association for the Gifted and Talented and currently moderated by Lisa Conrad. This live chat often includes a range of participants from different areas of gifted education: parents, teachers, researchers, clinicians, bloggers, and educational consultants. However, the majority of participants were teachers, gifted education consultants, and/or parents. Dr. Lucy Sanders is a clinical psychologist, educational consultant and personal wellness coach who also blogs about advocating for gifted children. Again, there is the pattern of large organizations and educational consultants being more influential in the gifted education affinity space in this study.

The top 20 influencers were determined by combining all the metrics. In addition to the accounts already discussed, the following accounts were identified: G-Word film, Dr. Jeffrey Mann (pseudonym), Duke Talent Identification Program (Duke TIP), Faye Stephens (pseudonym), Elizabeth Martin (pseudonym), Dr. Nina Townsend (pseudonym), Western Kentucky Center for Gifted Studies, Prufrock Press, Simon Holland (pseudonym), Arizona Association for Gifted and Talented (AAGT), and Dr. Terrence Ingram (pseudonym). The G-Word film, Duke TIP, the Western Kentucky Center for Gifted Studies and AAGT are all organizational accounts. The GWord film is a corporation working to raise money to produce a documentary about children and adults who have been identified as gifted. Duke TIP provided enrichment and acceleration for upper elementary, middle, and high school students and served as a base for research projects in gifted education. The program was discontinued by Duke University in 2020. The Western Kentucky Center for Gifted Studies is the account for a university-based program providing graduate level courses in gifted education and residential and summer programming for gifted students. Prufrock Press is a publisher of books and other educational resources related to gifted education. The Arizona Association for the Gifted and Talented is a state advocacy organization.

The following personal accounts were also identified as influencers. Dr. Jeffrey Mann coordinates a university-based continuing education program for teachers seeking an endorsement in gifted education and is a professional educational speaker. Faye Stephens is a writer, blogger, and educational consultant. Elizabeth Martin is a Master's level counselor and author specializing in working with twice-exceptional gifted children. Dr. Nina Townsend works at the university level in psychology and while her primary research area is outside the field of high cognitive ability and creativity, she also writes blogs and consults in gifted education. Simon Holland has a Master's degree in gifted education and works at the state level as a coordinator of gifted programming. Finally, Dr. Terrence Ingram is an associate professor of education, researcher, and speaker.

Of these top 20 influencers, six are individuals who primarily support themselves through work as educational consultants and paid speakers (Evelyn Simon, Dr. Lucy Sanders, Dr. Jeffery Mann, Faye Stephens, Elizabeth Martin, and Dr. Nina Townsend.) Although several of these individuals have other areas of employment, their primary connection to gifted education is 
through their consultancy work. Four of the 20 (NAGC, SENG, Mensa (American and British), and the Arizona Association for the Gifted and Talented) are large advocacy groups that hold conferences at the national or state level and often require membership fees. The inclusion of the Arizona Association for the Gifted and Talented as an influencer may have been driven by an increase in tweeting following the 2019 NAGC annual conference being held in the neighboring state of New Mexico followed by the lead up to the AAGT conference in February 2020. An additional four influential accounts were higher education centers that provide services for both teachers seeking coursework in gifted education and for students needing enrichment or acceleration (The Summer Institute for the Gifted, Belin-Blank Center, Duke TIP, and Western Kentucky Center for Gifted Studies.) Two of the influencers (Myra Patrick and Simon Holland) are educational professionals working at the state government level to advocate for gifted children. The remainder of the influencers were Prufrock Press, GT Chat, the G-Word documentary, and one doctoral level researcher, Terrence Ingram.

\section{Qualitative}

The qualitative results suggest that the dialogue in the gifted education community on Twitter is similar to what has been observed in previously conducted research. Knowledge dissemination (Xinga \& Goab, 2018) sharing research findings (Sugimoto et al., 2017), posting announcements (Kimmons et al., 2017), and self-promotion (Sultan et al., 2019) were all types of tweets that were seen in both previous studies and the current analysis. Luo et al. (2017) identified Twitter live chats as a popular way for multiple types of educational professionals to come together and discuss issues and share resources. This can be seen in the GT Chat account and interactions. Previous research has indicated several different motivations for individuals and educational professionals to participate in Twitter. The motivations of the individuals who were part of the affinity network in this study were not explored. There is an opportunity for further research in this area.

A large number of themes arose during the qualitative analysis. One of the challenges of using social media as personal learning networks is the range of needs and varied intensities of engagement (Goodyear et al., 2019). Teachers may engage with themes such as Curriculum and Programming or Gifted Teacher Ed while parents may be less interested in those topics and more engaged in tweets included in the themes of Parenting Gifted and Parent School Relationship. It is difficult to quantify engagement beyond measures such as numbers of followers and retweets. The data collection method used in this study provided information about how many times a tweet was retweeted, but not who saw the retweet and could have been influenced by it. Although there were diverse themes which spanned the potential interests of parents, teachers, and researchers, it is difficult to know if all participants engaged with all categories of top themes equally.

At the time that this study was being completed, several topics could be considered as top priorities or concerns in gifted education. As a nation, the United States is highly concerned with issues of equity and representation of diversity (of all kinds) in programs and courses provided for advanced learners. Underrepresentation of racial minorities has been a consistent educational concern and research interest in gifted education. A search on PsycNet using the terms "underrepresentation OR minority" and "gifted" yielded 425 results with the earliest journal 
article being Clark (1981). There has been a steady increase with 28 entries from 1980-1989, 68 from 1990-1999, 135 from 2000-2009, and 183 from 2010-2019. This may indicate increased interest or just an overall increase in publications related to gifted children. A search with the terms "gifted OR giftedness" from 1980 to 2021 resulted in 2,547 entries. There were 313 entries from 1980-1989, 559 from 1990-1999, 704 from 2000-2009, 923 from 2010-2019. A comparison among these metrics indicates that roughly $9 \%$ of articles in the $1980 \mathrm{~s}, 12 \%$ in the 1990 s, $19 \%$ in the 2000's and 20\% of articles in the 2010's were related to underrepresentation. A search on PsycNet using the terms "twice-exceptional OR 2e OR dual exceptionalities" and "gifted" generated 220 results with the earliest in the late 1990's (Cash, 1999). However, researchers were writing about the concept of dual exceptionalities without using those exact terms at least as early as 1980's (Yewchuk, 1983). The themes Underrepresented Groups and Twice-Exceptional Children as well as the associated topic of Assessment and Identification were top themes identified in this sample of tweets. Subsequent research can use the relative importance of these themes on Twitter as a point of comparison to evaluate possible shifting interests.

Parents of gifted children may have more personal concerns and may focus more on wanting their own children to be challenged and not dislike school. Parents are also often interested in the wholistic development of their child, including both cognitive development and social and emotional development. After the theme related to the Twitter chat, the relationship between parents and schools was the most frequently occurring topic. The topic of Parenting Gifted Children was also a top theme. A Pew Research Center survey found that $82 \%$ of parents who use social media indicated that they posted information about their children online, a practice that has been dubbed "sharenting" (Auxier et al., 2020). The use of Twitter to reach parents may be a missed opportunity for several major organizations. For example, NAGC, an identified influencer with a publication for parents, entitled Parenting for High Potential had only 13 posts that mentioned the publication in the 2020's at the time this manuscript was being prepared. Individuals or organizations that want to increase their influence on Twitter should be intentional in connecting with parents.

Although researchers and professors can have multiple identities or roles (i.e., parents and educators) and may post on many different topics, there were very few posts specific to research and only one of the top influencers was primarily a researcher. Twitter can be useful for researchers who can "push out" their work rather than waiting for others to pull the work from databases (Allen et al., 2013; Klar et al., 2020). This use of Twitter was not a major theme of the current sample. There is unrealized potential here for researchers to help parents and teachers sort through the chaff to get to the wheat of trustworthy concepts and important research findings. Psychologist Scott Lilienfeld recommended making sure that in addition to informing others about what does not work, one must also replace the debunked practice with advice about what parents and teachers can do to best meet their needs (Weir, 2014). With the increased interest in open science and democratization of science in the field of gifted education (McBee et al., 2018), rather than a missed opportunity, social media may provide greater access to findings to a more inclusive group of individuals, organizations, and stakeholders.

One voice that is not represented in this study is that of the student themselves. Exceptional cognitive ability is, by definition, a factor that makes these students different from their typically 
developing peers. This could lead them to seek support online. But few posts appeared to be from individuals under the age of 18. A likely reason is that younger children often have their social media use restricted and there is low use of Twitter by teens. A survey completed by the Statista corporation recorded that only $3 \%$ of minors use Twitter as opposed to $34 \%$ using the more popular site SnapChat and 29\% using TikTok (Tankovska, 2021). TikTok and SnapChat are not designed to relay messaging and information exchange with written words, thus it would be unlikely that individuals would use these applications in the same way that people use Facebook or Twitter.

In the past those who held the knowledge were considered the influencers. Beginning with the printing press and moving to the internet, the acquisition of knowledge became democratized. Contemporary influencers are those who know how to shape knowledge to further a personal, public, or professional agenda. Understanding how knowledge is transferred on these social media platforms informs the gifted education community how knowledge, including how research findings are disseminated to practitioners, clinicians, other academics, and parents, particularly during a time where disinformation and misinformation are serious matters of concern in mainstream media and on social media platforms. This study is one the first to examine Twitter discourse related the gifted education and one of only a few qualitative content analysis studies of Twitter discussions related to education. The qualitative analyses suggest that gifted education professionals and parents engage in Twitter in similar ways to what has been described in past research: to share interesting articles and videos, to discuss current issues, connect with like-minded others, and promote one's ideas, and seek opportunities. Quantitative social network research is a relatively new type of analysis, and this aspect of the study should be considered as exploratory. The main finding from this analysis is that gifted education Twitter appears to be a cohesive network and that the top influencers are organizations and educational consultants. A cohesive network can be useful in forwarding important findings, particularly as researchers seek to bridge the gap between research and practice. The drawbacks of a cohesive network should be noted. If an influencer should gain too much influence, self-styling themselves as a "guru" of sorts, there then becomes the tendency to ignore or dismiss the ideas of others, thus creating an echo chamber. Future research should examine if the pattern of influencers is similar for other areas of education and how individual teachers and educational researchers may better leverage their expertise to provide a more inclusive dissemination of knowledge. 


\section{References}

AERA ROGCT SIG [@AERA_GiftedSIG]. (2020, January 30). \#AERA20 will be here before we know it! Mark your calendar for these sessions and events from the @AERA_GiftedSIG \#gifted [Tweet]. Twitter. https://twitter.com/AERA_GiftedSIG/status/1222869068157349890

Alfredsson, E. K., \& Broberg, A. G. (2016). Universal parent support groups for parents of adolescents: Which parents participate and why? Scandinavian Journal of Psychology, 7(2), 177-184. https://doi.org/10.1111/sjop.12278

Allen, H. G., Stanton, T. R., Di Pietro, F., \& Moseley, G. L. (2013). Social Media Release Increases Dissemination of Original Articles in the Clinical Pain Sciences. PLoS ONE, 8(7). https://doi.org/10.1371/journal.pone.0068914

Alp, Z. Z., \& Öğüdücü, Ş. G. (2018). Identifying topical influencers on twitter based on user behavior and network topology. Knowledge-Based Systems, 141, 211-221. https://doi.org/10.1016/j.knosys.2017.11.021

Anspach, N. M., \& Carlson, T. B. (2018). What to believe? Social media commentary and belief in misinformation. Political Behavior, 42, 697-718. https://doi.org/10.1007/s11109-0189515-z

Auxier, B., Anderson, M., Perrin, A., \& Turner, E. (2020, August 27). Parents' attitudes—and experiences - related to digital technology. Pew Research Center: Internet, Science \& Tech. https://www.pewresearch.org/internet/2020/07/28/parents-attitudes-and-experiencesrelated-to-digital-technology/.

Baron, A., \& Townsend, R. (2017). Live tweeting by ambulance services: a growing concern. Journal of Paramedic Practice, 9(7). https://doi.org/10.12968/jpar.2017.9.7.282

Batrinca, B., \& Treleaven, P. C. (2015). Social media analytics: a survey of techniques, tools and platforms. AI \& Society, 30, 89-116. htpps://doi.org/10.1007/s00146-014-0549-4

Bellon-Harn, M. L., Ni, J., \& Manchaiah, V. (2020). Twitter usage about autism spectrum disorder. Autism, 24(7), 1805-1816. https://doi.org/10.1177/1362361320923173 journals.sagepub.com/home/aut

Bommarito, S. (2020). ARGUE LESS, TALK MORE: Engaging in productive conversation on social media. Literacy Today (2411-7862), 38(2), 20-22.

Borgatti, S. P., Everett, M. G., \& Johnson, J. C. (2018). Analyzing social networks (2 ${ }^{\text {nd }}$ ed.) SAGE.

Britt, V. G., \& Paulus, T. (2016). "Beyond the Four Walls of My Building": A Case Study of \#Edchat as a Community of Practice. American Journal of Distance Education, 30(1), 4859. https://doi.org/10.1080/08923647.2016.1119609

Brugnoli, E., Matteo, C., Quattrociocchi, W., \& Scala, A. (2019). Recursive patterns in online echo chambers. Scientific Reports, 9, 20118. https://doi.org/10.1038/s41598-019-56191-7

Burns, A. (2017). Blog. The Wiley-Blackwell Encyclopedia of Social Theory. https://doi.org/10.1002/9781118430873.est0578

Carpenter, J. P., \& Morrison, S. A. (2018). Enhancing teacher education . . . with Twitter? Phi Delta Kappan, 100 (1), 25-28. https://doi.org/10.1177/0031721718797118

Çelík, I. K., Büyüktíryakí, B., Cívelek, E., \& Kocabaş, C. N. (2019). Internet use habits of parents with children suffering from food allergy. Asthma Allergy Immunology, 17, 134139. https://doi.org/10.21911/aai.485

Clark, E. R. (1981). A double minority: The gifted Mexican American child. Spanish Speaking Mental Health Research Center Monographs, No 8, 21-33. 
Clifford, T., \& Minnes, P. (2013). Logging on: Evaluating an online support group for parents of children with Autism Spectrum Disorders. Journal of Autism and Developmental Disorders 43, 1662-1675. https://doi.org/10.1007/s10803-012-1714-6

Davis, K. (2015). Teachers' perceptions of Twitter for professional development. Disability and Rehabilitation, 37(17), 1551-1558. https://doi.org/10.3109/09638288.2015.1052576

Del Vicario, M. Bessi, A., Zollo, F., Petroni, F., Scala, A., Caldarelli, G., Stanley, H. E. \& Quattrociocchi, W. (2016). The spreading of misinformation online. PNAS, 113(3), 554559. www.pnas.org/cgi/doi/10.1073/pnas.1517441113

Domínguez S., \& Hollstein, B. (2014). Mixed methods social networks research: Design and applications. Cambridge University Press.

Doty, J. L., \& Dworkin, J. (2014) Online social support for parents: A critical review. Marriage \& Family Review, 50(2), 174-198. https://doi.org/10.1080/01494929.2013.834027

Dworkin, J., Rudi, J. H., \& Hessel, H. (2018). The state of family research and social media. Journal of Family Theory \& Review, 10, 796-813. https://doi.org/10.1111/jftr.12295

Eaton, P. W., \& Pasquini, L. A. (2020). Networked practices in higher education: A netnography of the \#AcAdvchat community. The Internet and Higher Education, 45, 100723. https://doi.org/10.1016/j.iheduc.2019.100723

Essaidi, A., Zaidouni, D., \& Bellafkih, M. (2020). New method to measure the influence of Twitter users. 2020 Fourth International Conference on Intelligent Computing in Data Sciences (ICDS), 1-5. https://doi.org/10.1109/ICDS50568.2020.9268726.

Findlay, K., \& van Rensburg, O. J. (2018). Using interaction networks to map communities on Twitter. International Journal of Market Research, 60(2), 169-189. https://doi.org/10.1177/1470785317753025

Fruchterman, T. M. J. \& Reingold, E. M. (1991), Graph drawing by force-directed placement. Practice \& Experience, 21(11), 1129-1164. https://doi.org/10.1002/spe.4380211102.

GHF Learners. [@gfhlearners]. (2020, January 6). What Exactly is Twice Exceptionality? It's not so much the services that made the difference in their success, but recognizing how [Tweet]. https://twitter.com/ghflearners/status/1214320849613938689

Giglietto, F., Rossi, L., \& Bennato, D. (2012). The Open Laboratory: Limits and possibilities of using Facebook, Twitter, and YouTube as a research data source. Journal of Technology in Human Services, 30(3-4), 145-159. https://doi.org/10.1080/15228835.2012.743797

Goodyear, V. A., Parker, M., \& Casey, A. (2019). Social media and teacher professional learning communities. Physical Education and Sport Pedagogy, 24(5), 421-433. https://doi.org/10.1080/17408989.2019.1617263

Greenhalgh, S. P., \& Koehler, M. J. (2017). 28 days later: Twitter hashtags as "just in time" teacher professional development. TechTrends, 61, 273-281. https://doi.org/10.1007/s11528-016-0142-4

gtchat. [@gtchatmod]. (2019, November 14). Hi, all! My tweets for the next hour will be devoted to Global \#gtchat (\#gifted \#talented) Powered by @TXGifted \#TAGT [Tweet]. Twitter. https://twitter.com/gtchatmod/status/1195144429088194560

Hass, M., Haley, K., Nagappan, B., \& Ankel, F (2020). The connected educator: personal learning networks. The Clinical Teachers' Toolbox, 17, 1-5 https://doiorg.ezproxy.csu.edu.au/10.1111/tct.13146

Hill, T. P. (1998). The first digit phenomenon. Scientific American, 86, 358-363.

Jang, S., Mckeever, B. W., Mckeever, R., \& Kim, J. K. (2019) From social media to mainstream news: The information flow of the vaccine-autism controversy in the US, Canada, and the 
UK. Health Communication, 34(1), 110-117.

https://doi.org/10.1080/10410236.2017.1384433

Jolly, J. L., \& Matthews, M. S. (2017) Why we blog: Homeschooling mothers of gifted children. Roeper Review, 39(2), 112-120. https://doi.org 10.1080/02783193.2017.1289579

Johns Hopkins CTY. [@CTYJohnsHopkins]. (2020, January 29). Is having your child skip a grade a good idea, or is there a better way to accelerate very bright [Tweet]. Twitter. https://twitter.com/CTYJohnsHopkins/status/1222626217670561792

Jürgens, P. (2012). Communities of communication: Making sense of the "Social" in social media. Journal of Technology in Human Services, 30(3-4), 186-203. https://doi.org/10.1080/15228835.2012.746079

Katz, E. (1957). The two-step flow of communication: An up-to-date report on an hypothesis. Political Opinion Quarterly, 21(1), 61-78. https://doi.org/10.1086/266687

Kim, A., \& Dennis, A. R. (2019). Says who? The effects of presentation format and source rating on fake news in social media. MIS Quarterly, 43(3), 1025-1039. https://doi.org/10.25300/misq/2019/15188

Kimmons, R., Veletsianos, G., \& Woodward, S. (2017). Institutional uses of Twitter in U.S. higher education. Innovations in Higher Education, 42, 97-111. https://doi.org/10.1007/s10755-016-9375-6

Klar, S., Krupnikov, Y., Ryan, J. B., Searles, K., \& Shmargad, Y. (2020). Using social media to promote academic research: Identifying the benefits of twitter for sharing academic work. PLOS ONE, 15(4). https://doi.org/10.1371/journal.pone.0229446

Külhaş Çelik, İ., Büyüktiryaki, B., Civelek, E., \& Kocabaş, C. N. (2019). Internet use habits of parents with children suffering from food allergy. Asthma Allergy Immunology, 17(3), 134-139. https://doi.org/10.21911/aai.485

Lerman, B. I., Lewis, S. P., Lumley, M., Grogan, G. J., Hudson, C. C., \& Johnson, E. (2017). Teen depression groups on Facebook: A content analysis. Journal of Adolescent Research, 32, 719-741. https://doi.org/10.1177/0743558416673717

Li, J., \& Greenhow, C. (2015). Scholars and social media: tweeting in the conference backchannel for professional learning. Educational Media International, 52(1), 1-14. https://doi.org/10.1080/09523987.2015.1005426

Lincoln, Y. S. \& Guba, E. G. (1985). Naturalistic Inquiry. Newbury Park, CA: Sage Publications.

Liu, B. (2012). Sentiment analysis and opinion mining. Morgan \& Claypool Publishers.

Luo, T., Sickel, J., \& Cheng, L. (2017). Preservice teachers' participation and perceptions of Twitter live chats as personal learning networks. Tech Trends, 61, 226-235. https://doi.org/10.1007/s11528-016-0137-1

Luzón, M. J., \& Albero-Posac, S. (2020). 'Had a lovely week at \#conference2018 ': An analysis of interaction through conference tweets. RELC Journal, 51(1), 33-51.

Manca, A., \& Whitworth, A. (2018). Social media and workplace practices in higher education institutions: A review. The Journal of Social Media in Society, 7(1), 151-183. https://www.thejsms.org/tsmri/index.php/TSMRI/article/viewFile/248/159

Marshall, T. C., Ferenczi, N., Lefringhausen, K., Suzanne Hill, S., \& Den, J. (2020). Intellectual, narcissistic, or Machiavellian? How twitter users differ from Facebook-only users, why they use twitter, and what they tweet about. Psychology of Popular Media, 9(1), 14-30. http://dx.doi.org/10.1037/ppm0000209 
McBee, M. T., Makel, M. C., Peters, S. J., \& Matthews, M. S. (2018). A call for open science in giftedness research. Gifted Child Quarterly, 62(4), 374-388. https://doiorg.proxy.library.vcu.edu/10.1177/0016986218784178

Merrill, J. T. [@ laughingatchaos]. (2020, January 9). A3 School MUST start by truly listening to parents \& their concerns. I lost track of the number of times I [Tweet]. https://twitter.com/laughingatchaos/status/1215445862408708096

Miles, M. B., Huberman, A. M., \& Saldaña, J. (2014). Qualitative data analysis (3 ${ }^{\text {rd }}$ ed.). SAGE. Mindshift. [@MindshiftKQED]. (2020, February 3). District leaders want to make sure qualified students who have been overlooked are truly integrated into the district's gifted program [Tweet]. https://twitter.com/MindShiftKQED/status/1224442971153522694

Mo, P. K. H., Malik, S. H., \& Coulson, N. S. (2009). Gender differences in computer-mediated communication: A systematic literature review of online health-related support groups. Patient Education and Counseling, 75(1), 16-24. https://doi.org/10.1016/j.pec.2008.08.029

NAGC. [@NAGCGIFTED]. (2019, November 11). "Treating giftedness as an in-born trait that can be identified by test scores has resulted in severe underrepresentation of highpotential children [Tweet]. https://twitter.com/NAGCGIFTED/status/1194062455225368576

National Science Board. (2018). Science and engineering indicators 2018. NSB-2018-1. National Science Foundation. https://www.nsf.gov/statistics/indicators/.

Nickerson, R. S. (1998). Confirmation bias: A ubiquitous phenomenon in many guises. Review of General Psychology, 2(2), 175-220. https://doi.org/10.1037/1089-2680.2.2.175

Nieuwboer, C. C., Fukkink, R. G., \& Hermanns, J. M. A. (2013). Online programs as tools to improve parenting: A meta-analytic review. Children and Youth Services Review, 35(11), 1823-1829. https://doi.org/10.1016/j.childyouth.2013.08.008

Niela-Vilén, H., Axelin, A., Salanterä, S., \& Melender, H-L. (2014). Internet-based peer support for parents: A systematic integrative review. International Journal of Nursing Studies, 51, 1524-1537. https://doi.org/10.1016/j.ijnurstu.2014.06.009

Park, C. S., \& Kaye, B.K. (2017). The tweet goes on: Interconnection of Twitter leadership, network size, and civic engagement. Computers in Human Behavior, 69, 174-180. https://doi.org/10.1016/j.chb.2016.12.021

Pei, S., Muchnik, L., Andrade, J. S., Zheng, Z., \& Makse, H. A. (2014). Searching for superspreaders of information in real-world social media. Scientific Reports, 4, 5547. https//www.doi.org/10.1038/srep05547

Pennebaker, J.W., Boyd, R. L., Jordan, K., \& Blackburn, K. (2015). The development and psychometric properties of LIWC2015. University of Texas at Austin. https//www.doi.org/10.15781/T29G6Z

Perrin, A., \& Anderson, M. (2019). Share of U.S. adults using social media, including Facebook, is mostly unchanged since 2018. https://www.pewresearch.org/facttank/2019/04/10/share-of-u-s-adults-using-social-media-including-facebook-is-mostlyunchanged-since-2018/

Peters, S. J. [@realScottPeters]. (2020, January 31). Everyone in gifted ed should read this article and this thread. So much really strong empirical work on \#gifted is [Tweet]. https://twitter.com/realScottPeters/status/1223324578249957377 
Pettigrew, S., Archer, C., \& Harrigan, P. (2016). A thematic analysis of mothers' motivations for blogging. Maternal Child Health Journal 20, 1025-1031 https://doi.org/10.1007/s10995015-1887-7.

Prestridge, S. (2019). Categorising teachers' use of social media for their professional learning: A self-generating professional learning paradigm. Computers \& Education, 129, 143158. https://doi.org/10.1016/j.compedu.2018.11.003

QDA Miner (2020). [Computer software]. https://provalisresearch.com/products/qualitative-dataanalysis-software/

Rehm, M., \& Notten, A. (2016). Twitter as an informal learning space for teachers!? The role of social capital in Twitter conversations among teachers. Teaching and Teacher Education, 60, 215-223. https://doi.org/10.1016/j.tate.2016.08.015

Ricoy. M. C., \& Feliz, T. (2016). Twitter as a learning community in higher education. Educational Technology \& Society, 19(1), 237-248. https://www.jstor.org/stable/jeductechsoci.19.1.237

Rinaldo, S. B., Tapp, S., \& Laverie, D. A. (2011). Learning by tweeting: Using Twitter as a pedagogical tool. Journal of Marketing Education 33(2), 193-203. https://doiorg.proxy.library.vcu.edu/10.1177/0273475311410852

Riquelme, F., Gonzalez-Cantergiani, P., Molinero, X., \& Serna, M. (2018). Centrality measure in social networks based on linear threshold model. Knowledge-Based Systems, 140, 92102. https://doi.org/10.1016/j.knosys.2017.10.029

Rodriguez, C. [@CTRodGT]. (2020, January 9). A2 I think it's critical that schools communicate what the research actually says about giftedness. There are so many myths [Tweet]. https://twitter.com/CTRodGT/status/1215443598864461824

Ross, C. R., Maninger, R. M., LaPrairie, K. N., \& Sullivan, S. (2015). The use of twitter in the creation of educational professional learning opportunities. Administrative Issues Journal: Connecting Education, Practice, and Research, 5(1), 55-76. http://dx.doi.org/10.5929/2015.5.1.7

Scheufele, D. A., \& Krause, N. M. (2019). Science audiences, misinformation, and fake news. Proceedings of the National Academy of Sciences, 116(16), 7662-7669.

https://doi.org/10.1073/pnas.1805871115

Segota, J. [@JohnSegota]. (2020, January 27). "When advanced opportunities are extended to students of color and when teachers receive training and resources, these students thrive alongside [Tweet]. https://twitter.com/JohnSegota/status/1221888638264455171

SENG. [@SENG_Gifted]. (2019, November 9). Having high sensitivity makes \#gifted individuals especially susceptible to mental health issues, such as depression and anxiety. Sound familiar? [Tweet]. https://twitter.com/SENG_Gifted/status/1193294728118317061

Sepp, M., Liljander, V., \& Gummerus, J. (2011). Private bloggers' motivations to produce content-A gratifications theory perspective. Journal of Marking Management, 27, 1479-1503. doi: 10.1080/0267257X.2011.624532

Shepherd, D., Goedeke, S., Landon, J., \& Meads, J. (2020). The types and functions of social supports used by parents caring for a child with autism spectrum disorder. Journal of Autism and Developmental Disorders, 50, 1337-1352. https://doi.org/10.1007/s10803019-04359-5 
Shoemaker, J. [@jeff_shoemaker]. (2020, January 8). Taking something away from some is not equity for all. Expand programs, use different methods of identification. Elimination is just [Tweet]. https://twitter.com/jeff_shoemaker/status/1214892524734730240

Smith, M., Ceni A., Milic-Frayling, N., Shneiderman, B., Mendes Rodrigues, E., Leskovec, J., Dunne, C., (2010). NodeXL: a free and open network overview, discovery and exploration add-in for Excel 2007/2010/2013/2016, from the Social Media Research Foundation: https://www.smrfoundation.org

Smith, M. A., Rainie, L., Scneiderman, B., \& Himelboim, I. (February 20, 2014). Mapping Twitter topic networks: From polarized crowds to community clusters. Pew Research Center. https://www.pewresearch.org/internet/2014/02/20/mapping-twitter-topicnetworks-from-polarized-crowds-to-community-clusters/

Smith-Risser, H. (2013). Virtual induction: A novice teacher's use of Twitter to form an informal mentoring network. Teaching and Teacher Education, 35, 25-33. https://doi.org/10.1016/j.tate.2013.05.001

Snelson, C. L. (2016). Qualitative and mixed methods social media research. International Journal of Qualitative Methods, 15(1), 160940691562457. https://doi.org/10.1177/1609406915624574

Statista. (January 27, 2020). Most popular social networks worldwide as of October 2020, ranked by number of active users. https://www.statista.com/statistics/272014/globalsocial-networks-ranked-by-number-of-users/

Staudt Willet, K. B. (2019). Revisiting How and Why Educators Use Twitter: Tweet Types and Purposes in \#Edchat. Journal of Research on Technology in Education, 51(3), 273-289. https://doi.org/10.1080/15391523.2019.1611507

Stevenson, M., Hedberg, J. G., O’Sullivan, K., \& Howe, C. (2015). Development to learning: semantic shifts in professional autonomy and school leadership. Educational Media International, 52(3), 173-187. http://dx.doi.org/10.1080/09523987.2015.1075100

Strauss, A., \& Corbin, J. (1998). Basics of qualitative research: techniques and procedures for developing grounded theory. Sage Publications.

Sultan, M., Brown, E. M., \& Thomas, R. H. (2019). Clinicians embracing social media: Potential and pitfalls. Epilepsy \& Behavior, 106462. https://doi.org/10.1016/j.yebeh.2019.106462

Sugimoto, C. R., Work, S., Larivière, V., \& Haustein, S. (2017). Scholarly use of social media and altmetrics: A review of the literature. Journal of the Association for Information Science and Technology, 68(9), 2037-2062. https://doiorg.proxy.library.vcu.edu/10.1002/asi.23833

Swire-Thompson, B., \& Lazer, D. (2020). Public health and online misinformation: Challenges and recommendations. Annual Review of Public Heath, 41, 433-451. https://doi.org/10.1146/annurev-publhealth-040119-094127

Tankovska, H. (2021, January 28). Social networks used by teens in U.S. Statista. https://www.statista.com/statistics/250172/social-network-usage-of-us-teens-and-youngadults/\#statisticContainer.

Tifferet, S. (2020). Gender differences in social support on social network sites: A meta-analysis. Cyberpsychology, Behavior, and Social Networking, 23(4). https://doi.org/10.1089/cyber.2019.0516

Tinati, R., Halford, S., Carr, L., \& Pope, C. (2014). Big data: Methodological challenges and approaches for sociological analysis. Sociology, 48(4), 663-681. https://doi.org/10.1177/0038038513511561 
Trust, T., Carpenter, J. P., \& Krutkac, D. G. (2018). Leading by learning: exploring the professional learning networks of instructional leaders. Educational Media International, 55(2), 137-152. https://doi.org/10.1080/09523987.2018.1484041

Tsugawa, S., \& Kimura, K. (2018). Identifying influencers from sampled social networks. Physica A: Statistical Mechanics and its Applications, 507, 294 - 303. https://doi.org/10.1016/j.physa.2018.05.105

Tucker, L. (2019). Educational professionals' decision making for professional growth using a case of twitter adoption. TechTrends, 63, 133-148. https://doi.org/10.1007/s11528-0180346-x

Veletsianos, G., \& Kimmons, R. (2016). Scholars in an increasingly open and digital world: How do education professors and students use Twitter? Internet and Higher Education 30, 110. http://dx.doi.org/10.1016/j.iheduc.2016.02.002

Vosoughi, S., Roy, D., \& Aral, S. (2018). The spread of true and false news online. Science, 359(6380), 1146-1151. https://doi.org/10.1126/science.aap9559

Wang, Y., McKee, M., Torbica, A., \& Stuckler, D. (2019). Systematic literature review on the spread of health-related misinformation on social media. Social Science \& Medicine, 240, 112552. https://doi.org/10.1016/j.socscimed.2019.112552

Wenger, E. (2005). Communities of practice. A brief introduction. https://scholarsbank.uoregon.edu/xmlui/handle/1794/11736

Weir, K. (2014, October). Translating psychological science. Monitor on Psychology. https://www.apa.org/monitor/2014/10/translating-science

Wojcik, S., \& Hughes, A. (2019) Sizing up Twitter users U.S. Pew Research Center. https://www.pewresearch.org/internet/2019/04/24/sizing-up-twitter-users/

Wood, M. J. (2018). Propagating and debunking conspiracy theories on Twitter during the 20152016 Zika Virus Outbreak. Cyberpsychology, Behavior, and Social Networking, 21(8), 485-490. https://doi.org/10.1089/cyber.2017.0669

Xinga, W., \& Gaob, F. (2018). Exploring the relationship between online discourse and commitment in Twitter professional learning communities. Computers \& Education, 126, 388-398. https://doi.org/10.1016/j.compedu.2018.08.010

Yewchuk, C. (1983). Learning disabled/gifted children: Characteristic features. Mental Retardation and Learning Disability Bulletin, 11, 128-133.

Zalaznick, M. [@ zalaznick]. (2020, January 28). Twice-exceptional \#students: What \#school districts need to know \#specialeducation \#gifted [Tweet]. https://twitter.com/Zalaznick/status/1222115451095912448

Zhang, Z., \& Ahmed, W. (2019). A comparison of information sharing behaviours across 379 health conditions on Twitter. International Journal of Public Health, 64, 431-440. https://doi.org/10.1007/s00038-018-1192-5

Zollo, F., Bessi, A., Del Vicario, M., Scala, A., Caldarelli, G., Shekhtman, L., Shlomo, H., \& Quattrociocchi, W. (2017). Debunking in a world of tribes. PLoS ONE 12(7), e0181821. https://doi.org/10.1371/journal.pone.0181821

Zyoud, S. H., Sweileh, W. M., Awang, R., \& Al-Jabi. S. W. (2018). Global trends in research related to social media in psychology: mapping and bibliometric analysis. International Journal of Mental Health Systems, 12(4). https://doi.org/10.1186/s13033-018-0182-6 